\title{
Reduced E-cadherin facilitates renal cell carcinoma progression by WNT/ $\beta$-catenin signaling activation
}

\author{
Xinqi Zhang ${ }^{1}$, Mingxi Yang ${ }^{2}$, Hua Shi ${ }^{2}$, Jianxin $\mathrm{Hu}^{2}$, Yuanlin Wang ${ }^{2}$, Zhaolin Sun ${ }^{2}$, Shuxiong \\ $\mathbf{X} \mathbf{u}^{2}$ \\ ${ }^{1}$ Emergency Department, General Hospital of Jinan Military Area, Jinan, Shandong, 250031, China \\ ${ }^{2}$ Department of Urology, Guizhou Provincial People's Hospital Affiliated to Guizhou Medical University, Guiyang, Guizhou, \\ 550002, China
}

Correspondence to: Shuxiong Xu, email: xushuxong123@sina.com

Keywords: renal cell carcinoma, E-cadherin, $\beta$-catenin, immunohistochemistry (IHC)

Received: September 26, 2016

Accepted: January 16, 2017

Published: February 15, 2017

\section{ABSTRACT}

Reduced expression of E-cadherin was observed in renal cell carcinoma (RCC). However, its potential clinical value and correlation with WNT/ $\beta$-catenin signaling in RCC progression was still unclear. Immunohistochemical staining was performed in RCC tissue microarray to examine the expression status and prognosis value of $E$-cadherin and $\beta$-catenin. The potential role of E-cadherin in $\beta$-catenin translocation was analyzed with immunobloting assays. A significant negative correlation was observed between E-cadherin and $\beta$-catenin expression in RCC tissues. E-cadherin inhibits $\beta$-catenin translocation from membrane to cytoplasm in RCC tissues, which was an important step for WNT/ $\beta$-catenin signaling. Reduced E-cadherin expression was associated with poor prognosis. More importantly, E-cadherin-/ $\beta$-catenin ${ }^{+}$was an independent detrimental factor for survival estimation of RCC patients. Reduced E-cadherin expression in RCC promoted cancer progression via WNT/ $\beta$-catenin signaling pathway activation. E-cadherin/ $\beta$-catenin provides a valuable prognosis marker for RCC, which may be an effective target for RCC therapy.

\section{INTRODUCTION}

Renal cell carcinoma (RCC) is one of the most common malignant tumor in urinary system with high mortality [1]. Increased incidence was observed during the last decades [2]. Nearly $40 \%$ of the RCC patients were died from cancer progression [3]. The prognosis markers are valuable for RCC patients. However, the exact mechanisms which promote the progression of RCC are still unclear.

Accumulated evidences supported that the deregulation of cell-to-cell adhesion molecules were involved in RCC progression, which promoted tumor cell invasion and metastatic activity $[4,5]$. As a calciumdependent cell adhesion molecule, E-cadherin maintains the integrity of epithelial cells by regulating actin cytoskeleton. Reduced E-cadherin expression or mutation induced function loss of the cadherin complex, which resulted in metastasis of epithelial malignancies [6-8]. However, the clinical value of E-cadherin in diagnosis and prognosis evaluation was still unclear in RCC.

As an important member of cadherin complex, $\beta$-catenin is involved in $\mathrm{Ca}^{2+}$-dependent, cell-to-cell adhesion maintains of epithelial cells [9]. The disruption of E-cadherin/ $\beta$-catenin complex activates tumor metastasis in a series of epithelial malignancies [10-13]. Moreover, $\beta$-catenin works as a key factor of canonical WNT signaling pathway. Dysregulation of $\mathrm{WNT} / \beta$-catenin signaling results in abnormal accumulation of $\beta$-catenin in cytoplasm of cancer cells, to develop a complex with a group of transcription factors $[14,15]$. Thereby elevated canonical WNT signaling targeted genes are involved in carcinogenesis and progression $[9,16]$. However, the clinical value of WNT signaling dysregulation in RCC is still not clear. Here, we focused on the deregulation of E-cadherin in RCC progression based on tissue microarray analysis, as well as its potential correlation with $\mathrm{WNT} / \beta$-catenin signaling pathway.

\section{RESULTS}

E-cadherin expression and correlation with clinicopathological characteristics

IHC staining for E-cadherin was performed on TMA slides of RCCs. E-cadherin expression status was classified 
by the Allred score, score $\geq 4$ was positive and score $<4$ was negative. Stained E-cadherin protein was located on the cell membrane, which was arranged as brownish yellow granular or linear (Figure 1A). E-cadherin expression was observed in some renal tubules, but rarely found in nephron in the adjacent normal tissue (Supplementary Figure 1A). Significant decreased E-cadherin expression level was observed in the tumor tissue than adjacent normal tissue (Figure 1A and Supplementary Figure 1A). Moreover, lower positive percentage of E-cadherin expression was also observed in the tumor tissue (44/125) than adjacent normal tissue $(106 / 125)\left(35.2 \%\right.$ vs. $84.8 \%, \chi^{2}=48.923$, $P<0.001$, Figure 1B).

Further analysis of E-cadherin expression and clinicopathological characteristics was also performed. Notably, significant correlation was observed in histological type $(p<0.001)$. Significant lower percentage of E-cadherin expression was observed in clear cell renal carcinoma (7/67) than other types (37/58) (10.45\% vs. $63.79 \%$ ). However, no significant correlation was observed between E-cadherin expression and age, gender, clinical stage, Fuhrman grade and necrosis $(P>0.05$, Table 1$)$.

\section{Prognosis value of E-cadherin expression in RCC patients}

Kaplan-Meier (KM) analyses for disease-free survival (DFS) and overall survival (OS) were performed to investigate the prognostic value of E-cadherin expression in RCC. All the patients involved in our study were followed-up and the median period of 52.27 months (range: 22.8-152.6 months). Disease progression was observed in 21 patients $(16.80 \%)$ during the period. Distant metastasis was observed with $95.24 \%$ of disease-progressed patients (20/21). The survival analysis revealed that E-cadherin patients showed no significant difference in overall survival estimation (OS) compared to other patients $(P=0.062$. Figure $1 C)$. However, significant benefit was observed for those patients with RCC positive for E-cadherin ( $P=0.031$. Figure 1D). To evaluate the independent prognostic significance of E-cadherin expression, a univariate analysis was performed with E-cadherin status (Table 2). The results showed that E-cadherin negative expression was a significant detrimental factor for DFS $(\mathrm{HR}=0.229, P=0.049)$, but not for OS $(\mathrm{HR}=0.028$, $P=0.266$, Table 2). Furthermore, multivariate analyses were also performed with E-cadherin expression status. Factors associated with prognosis of RCC were included, such as age, gender, tumor size, tumor stage, Fuhrman grade and necrosis. The result indicated that E-cadherin expression was a beneficial factor for patients' DFS (HR $=0.0 .206$, 95\% CI: 0.046-0.928, $P=0.040)$. However, no significant correlation was observed with OS (HR $=0.000$, 95\% CI: $0.000-4.007 \mathrm{E} 205, P=0.960$. Table 3). In addition, higher age had positive impact on both DFS (HR $=0.281$, 95\% CI: $0.101-0.786, P=0.016)$ and $\mathrm{OS}(\mathrm{HR}=0.149,95 \%$ CI: $0.028-0.786, P=0.025$. Table 3). Our data suggested that reduced E-cadherin expression was correlated with progression of RCC.

\section{E-cadherin expression correlated with WNT/ $\beta$-catenin signaling}

To investigate the underlie mechanism of E-cadherin participated RCC progression, Western blot assays for WNT/ $\beta$-catenin signaling was performed in four fresh clinical specimens. Increased WNT/ $\beta$-catenin signaling activation was observed in E-cadherin negative specimens, whereas inhibited WNT/ $\beta$-catenin signaling in E-cadherin positive ones (Figure 2A). Further RT-PCR assays were performed with clinical specimens for Wnt/ $\beta$-catenin targeted genes, including c-myc and cyclin D1. Elevated expression of Wnt $/ \beta$-catenin targeted genes was shown in E-cadherin negative specimens (Figure 2A and 2B). To further investigate the correlation of E-cadherin and $\mathrm{Wnt} / \beta$-catenin signaling, we carried out immunobloting assays to investigate the translocation of $\beta$-catenin in fresh RCC tissues. We found that $\beta$-catenin was concentrated in the membrane in E-cadherin positive specimens (Figure $2 \mathrm{C}$ ). Increased $\beta$-catenin translocation for membrane to cytoplasm was observed in E-cadherin negative speicimes than E-cadherin positive ones (Figure 2D). Our results suggested a potential role of $\mathrm{WNT} / \beta$-catenin signaling in the progression of E-cadherin negative RCC.

\section{$\beta$-catenin expression and correlations with E-cadherin in RCC}

Another IHC staining for $\beta$-catenin was performed with TMA specimens of RCC. Positive staining of $\beta$-catenin was located in cell membrane/cytoplasm (Figure 3A, 3B and Supplementary Figure 1B). More importantly, $\beta$-catenin expression in RCC cells was decreased or disappeared in membrane (Figure 3A), whereas abnormal accumulation in cytoplasm (Figure 3B). About $71.2 \%$ of renal cell carcinoma specimens were positive for $\beta$-catenin $(89 / 125$, Figure $3 \mathrm{C}$ ). These results provided further evidence of the translocation of $\beta$-catenin from membrane to cytoplasm in RCC. Further analysis for the correlation of E-cadherin and $\beta$-catenin expression was performed. Lower percentage of E-cadherin expression was observed in $\beta$-catenin positive specimens than negative ones $(26.97 \%$ vs. $55.56 \%$, $P<0.01$, Figure 3C and Supplementary Figure 2A, 2B). Moreover, significant negative correlation was observed between $\beta$-catenin scores and E-cadherin scores according to a linear regression analyze $\left(R^{2}=0.120, P<0.0001\right.$, Figure $3 \mathrm{D})$. Our results suggested a negative correlation between $\beta$-catenin and E-cadherin expression in RCC.

\section{Correlations between $\beta$-catenin and clinicopathological characteristics}

In RCC specimens, significantly increased $\beta$-catenin expression was observed in higher Fuhrman grade tissues 


\begin{tabular}{|c|c|c|c|}
\hline \multirow{2}{*}{ Variables } & \multicolumn{2}{|c|}{ E-cadherin Expression } & \multirow{2}{*}{ "p Value } \\
\hline & High & Low & \\
\hline \multicolumn{4}{|l|}{ Gender } \\
\hline Male & 25 & 58 & 0.095 \\
\hline Female & 19 & 23 & \\
\hline \multicolumn{4}{|l|}{ Age (years) } \\
\hline$>56$ & 24 & 38 & 0.415 \\
\hline$\leq 56$ & 20 & 43 & \\
\hline \multicolumn{4}{|l|}{ Surgical procedure } \\
\hline Partial nephrectomy & 10 & 14 & 0.461 \\
\hline Radical nephrectomy & 34 & 67 & \\
\hline \multicolumn{4}{|l|}{ Tumor size, cm } \\
\hline$<5.25$ & 25 & 38 & 0.290 \\
\hline$>5.25$ & 19 & 43 & \\
\hline \multicolumn{4}{|l|}{ TNM stage } \\
\hline $\mathrm{I}-\mathrm{II}$ & 32 & 61 & 0.752 \\
\hline III-IV & 12 & 20 & \\
\hline \multicolumn{4}{|l|}{ Histological subtype } \\
\hline Clear cell & 7 & 60 & $<0.001$ \\
\hline Papillary & 16 & 12 & \\
\hline Chromophobe & 18 & 1 & \\
\hline Others & 3 & 8 & \\
\hline \multicolumn{4}{|l|}{ Necrosis } \\
\hline Yes & 11 & 23 & 0.684 \\
\hline No & 33 & 58 & \\
\hline \multicolumn{4}{|l|}{ Fuhrman grade } \\
\hline G1-2 & 25 & 46 & 0.998 \\
\hline G3-4 & 19 & 35 & \\
\hline
\end{tabular}

${ }^{*} P$ value was estimated with Chi-square test.

than lower ones (Fuhrman grade 3-4 vs. 1-2, $P=0.030$, Table 3). However, no significant correlation was observed in $\beta$-catenin expression and other variables, including age, gender, tumor size, clinical stage, histological type and necrosis $(P>0.05$, Table 3$)$. Our results suggested that the activated WNT/ $\beta$-catenin signaling was a potential detrimental actor for RCC patients.

\section{Prognostic value of $\mathbf{E}$-cadherin/ $\boldsymbol{\beta}$-catenin expression in RCC}

Further study was performed to study the prognostic value of $\beta$-catenin expression in RCC. Significant worse DFS was observed in $\beta$-catenin positive patients than negative ones $(P=0.027$, Figure $4 \mathrm{~A})$. However, no significant difference was observed in OS between two groups $(P=0.074$, Figure 4B). Further survival analysis revealed that E-cadherin/ $/ \beta$-catenin ${ }^{+}$patients showed significant worse prognosis in both OS and DFS compared to other patients $(P=0.014, p=0.011$. Figure 4C, 4D).

To evaluate the independent prognostic significance of E-cadherin $/ \beta$-catenin ${ }^{+}$, a univariate analysis was performed with E-cadherin $/ \beta$-catenin ${ }^{+}$(Table 4). The results showed that $\mathrm{E}$-cadherin $/ \beta$-catenin ${ }^{+}$expression was a significant detrimental factor for DFS (HR $=3.433$, 95\% CI: $1.249-9.433, P=0.017)$ and $\mathrm{OS}(\mathrm{HR}=8.761$, $95 \%$ CI: 1.103-69.556, $P=0.0 .040$. Table 4). Furthermore, multivariate analyses were performed with combined expression status of E-cadherin- $/ \beta$-catenin + . Our results indicated that E-cadherin- $/ \beta$-catenin + co-expression was significantly associated with patients' poor DFS $(\mathrm{HR}=4.105,95 \% \mathrm{CI}: 1.329-12.681, P=0.030)$, but not associated with OS (HR $=4.006,95 \%$ CI: $0.903-68.373$, $P=0.222$. Table 4). In addition, higher tumor stage had negative impact on DFS (HR $=1.891,95 \%$ CI: $1.036-3.454$, $P=0.038$. Table 4). 


\section{DISCUSSION}

The complex of E-cadherin/ $\beta$-catenin attaches to actin cytoskeleton to regulate cell adhesion [17]. Loss function of E-cadherin complex will result in reduced cell adhesion and elevated tumor migration [18-21]. Combined allelic loss (16q) and point mutation in the remaining allele, as well as aberrant methylation of $\mathrm{CpG}$ islands in its promoter, result in reduced E-cadherin expression in malignances [22]. More importantly, increased E-cadherin expression in RCC cells inhibits tumor growth and prolongs survival in vitro [23]. Although the significance of E-cadherin in malignant biological behavior is well analyzed, the clinical value of E-cadherin expression in RCC is still under investigation. In this study, we observed reduced or loss of E-cadherin protein expression in the majority of examined RCC tissue microarray, especially clear cell renal carcinoma. More importantly, reduced E-cadherin expression was a significant detrimental

A

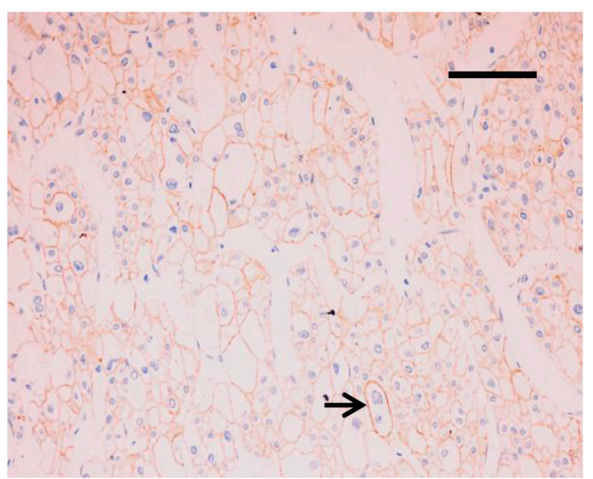

C

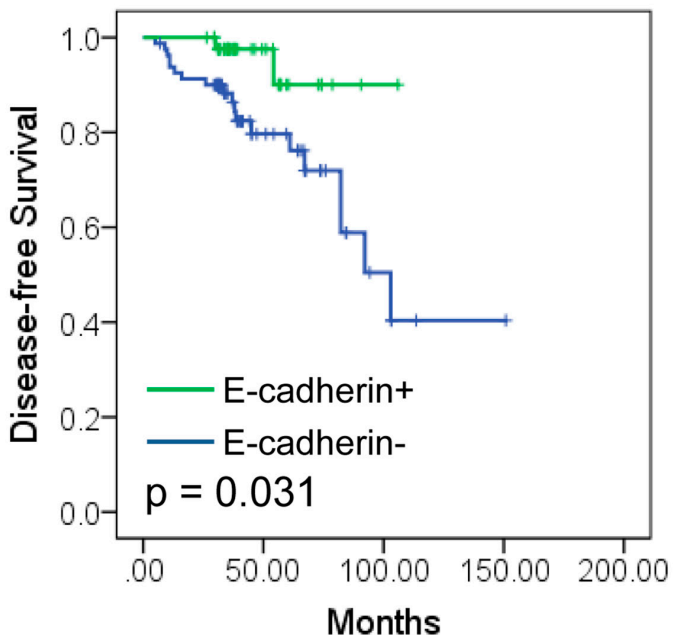

B

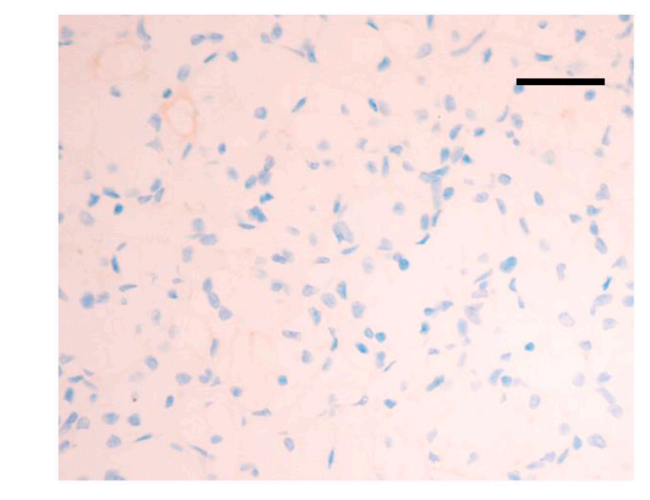

B

D

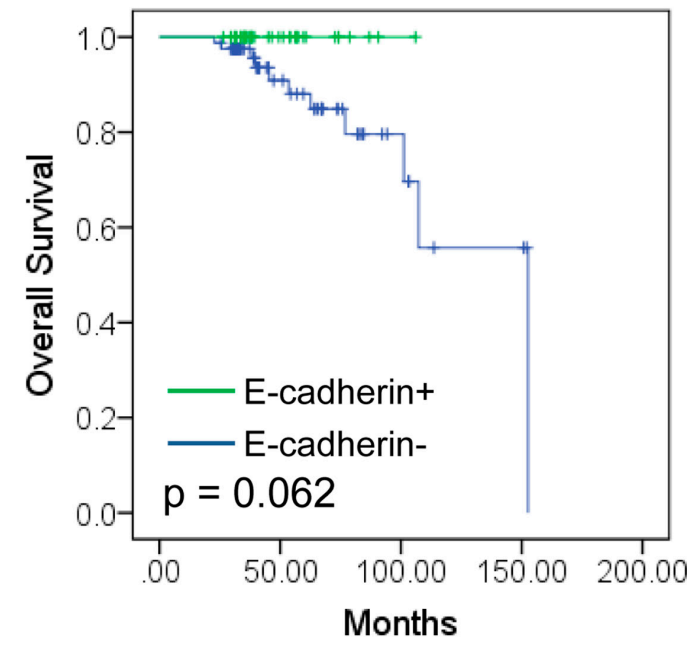

factor for the prognosis of RCC. Increased disease progression was observed in the patients with E-cadherin negative RCCs. Moreover, significant reduced E-cadherin expression and increased metastasis were observed in clear cell renal cell carcinoma. Further study will be performed for the potential basic mechanism and clinical value.

A variety of signaling pathways have already shown to be involved in carcinogenesis and progression of RCC, including PI3K/Akt/mTOR, HGF/Met and VHL/ hypoxia cellular signaling [24-27]. Recent studies have also shown aberrant signal transduction of WNT/ $\beta$-catenin is correlated with an aggressive phenotype $[15,28,29]$. However, the exact mechanisem of WNT/ $\beta$-catenin classical pathway involved in RCC progression is still under investigation. Interestingly, previous studies and our study declared that $\mathrm{WNT} / \beta$-catenin pathway is deregulated especially in poorly differentiated and late-staged RCCs $[30,31]$. E-cadherin shows a clear membranous staining pattern, whereas $\beta$-catenin shows a cytoplasmic

Figure 1: E-cadherin expression and prognosis value in RCC. (A, B) E-cadherin expression images of RCC specimens. Positive E-cadherin expression was located on the membrane (A, black arrow) and negative E-cadherin expression image (B). Bar, $50 \mu \mathrm{m}$. (C, D) KaplanMeier analysis of disease-free survival (DFS, C) and Overall survival (OS, D) of RCC patients according to E-cadherin expression status. 
Table 2: Univariate and multivariate analyses of E-cadherin expression in disease-free survival and overall survival

\begin{tabular}{lcccccc}
\hline \multicolumn{1}{c}{$\begin{array}{l}\text { Variable } \\
\text { analysis }\end{array}$} & \multicolumn{3}{c}{ Disease-Free Survival } & \multicolumn{3}{c}{ Overall Survival } \\
\cline { 2 - 6 } Univariate & $N=125$ & $\mathbf{9 5 \%}$ CI & $\boldsymbol{p}$ & HR & $\mathbf{9 5 \%}$ CI & $\boldsymbol{p}$ \\
E-cadherin & 0.229 & $0.053-0.991$ & 0.049 & 0.028 & $0.001-15.090$ & 0.266 \\
Multivariate & $N=125$ & & & $N=125$ & & \\
Gender & 0.749 & $0.279-2.008$ & 0.565 & 0.541 & $0.111-2.637$ & 0.447 \\
Age & 0.281 & $0.101-0.786$ & 0.016 & 0.149 & $0.028-0.786$ & 0.025 \\
Size & 0.708 & $0.209-2.400$ & 0.579 & 0.505 & $0.061-4.207$ & 0.528 \\
Stage & 1.779 & $1.007-3.142$ & 0.047 & 2.165 & $0.951-4.930$ & 0.066 \\
Necrosis & 2.346 & $0.734-7.500$ & 0.150 & 1.298 & $0.250-6.750$ & 0.756 \\
Fuhrman & 1.249 & $0.736-2.118$ & 0.409 & 1.868 & $0.841-4.150$ & 0.125 \\
E-cadherin & 0.206 & $0.046-0.928$ & 0.040 & 0.000 & $0.000-4.007 \mathrm{E} 205$ & 0.960 \\
\hline
\end{tabular}

The variables were compared in the following ways: Age, $\geq 57$ years vs. $<57$ years; Gender, male vs. female; E-cadherin expression, positive vs. negative; size, $>5.25$ vs. $<5.25$; Stage, III-IV vs. I-II; Necrosis, yes vs. no; Fuhrman grade, G3-4 vs. G1-2.
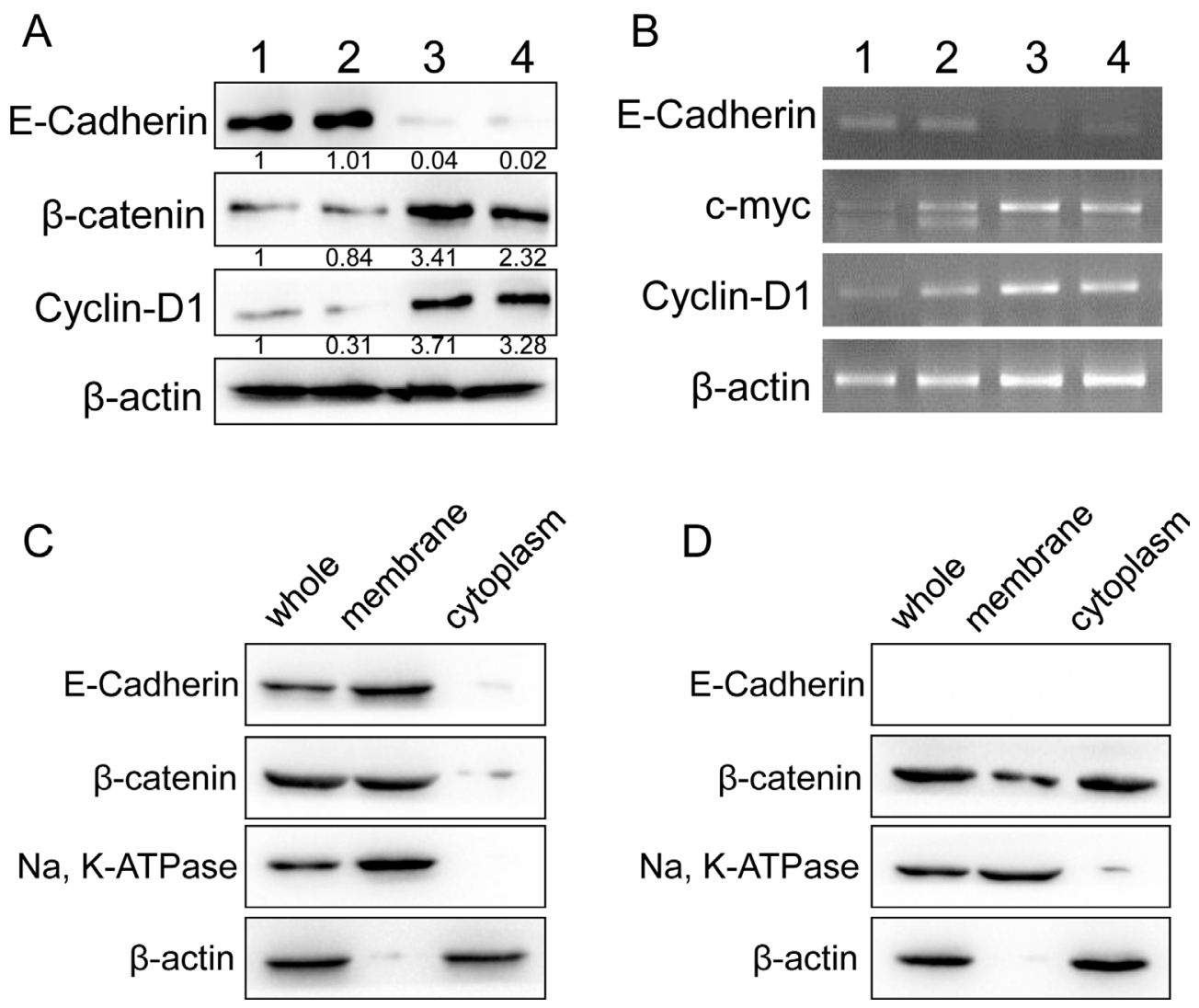

Figure 2: Correlation between E-cadherin and WNT/ $\beta$-catenin signaling in RCC tissues. (A) E-cadherin, $\beta$-catenin and cyclin D1 protein levels were analyzed with western blot in four fresh RCC tissues. $\beta$-actin was used as loading control. (B) mRNA levels of E-cadherin and WNT/ $\beta$-catenin signaling targeted genes was studied with RT-PCR in the four fresh RCC tissues. $\beta$-actin was used as control. (C, D) $\beta$-catenin location in E-cadherin positive (C) or negative (D) specimens were studied with immunobloting assays. $\mathrm{Na}, \mathrm{K}$ ATPase was used as membrane control, and $\beta$-actin as cytoplasm control. Representative images from at least three independent experiments are shown. 
Table 3: Correlations of $\beta$-catenin and clinical characteristics

\begin{tabular}{|c|c|c|c|}
\hline \multirow{2}{*}{ Variables } & \multicolumn{2}{|c|}{$\beta$-catenin expression } & \multirow{2}{*}{$P$ Value } \\
\hline & High & Low & \\
\hline \multicolumn{4}{|l|}{ Gender } \\
\hline Male & 63 & 20 & 0.103 \\
\hline Female & 26 & 16 & \\
\hline \multicolumn{4}{|l|}{ Age (years) } \\
\hline$>56$ & 42 & 20 & 0.397 \\
\hline$\leq 56$ & 47 & 16 & \\
\hline \multicolumn{4}{|l|}{ Surgical procedure } \\
\hline Partial nephrectomy & 14 & 10 & 0.121 \\
\hline Radical nephrectomy & 75 & 26 & \\
\hline \multicolumn{4}{|l|}{ Tumor size, $\mathrm{cm}$} \\
\hline$<5.25$ & 41 & 22 & 0.128 \\
\hline$>5.25$ & 48 & 14 & \\
\hline \multicolumn{4}{|l|}{ TNM stage } \\
\hline I-II & 69 & 24 & 0.208 \\
\hline III-IV & 20 & 12 & \\
\hline \multicolumn{4}{|l|}{ Histological subtype } \\
\hline Clear cell & 56 & 11 & 0.222 \\
\hline Papillary & 9 & 19 & \\
\hline Chromophobe & 17 & 2 & \\
\hline Others & 7 & 4 & \\
\hline \multicolumn{4}{|l|}{ Necrosis } \\
\hline Yes & 28 & 6 & 0.092 \\
\hline No & 61 & 30 & \\
\hline \multicolumn{4}{|l|}{ Fuhrman grade } \\
\hline G1-2 & 45 & 26 & 0.030 \\
\hline G3-4 & 44 & 10 & \\
\hline
\end{tabular}

${ }^{*} P$ value was estimated with Chi-square test.

and membranous localization. Our study indicated that accumulated $\beta$-catenin cytoplasmic expression in the absence of E-cadherin expression in RCC tissues, which was correlated with tumor invasiveness and poor prognosis. We provided further evidence that accumulation of $\beta$-catenin was associated with advanced Fuhrman grade. Additionally, we showed that more renal clear cell carcinomas exhibited increased $\beta$-catenin expression, which was just the opposite of E-cadherin.

In the current study, we co-analyzed the clinical value of E-cadherin/ $\beta$-catenin protein complex in RCC specimens. Importantly, the cytoplasmic accumulation of $\beta$-catenin protein and reduced expression of E-cadherin were associated with an aggressive biological behavior of RCCs [32, 33]. Worse prognosis was estimated for the patients with E-cadherin $/ \beta$-catenin ${ }^{+}$RCCs, which further support that $\mathrm{WNT} / \beta$-catenin classical signaling participated in the progression of RCCs. This event potentially explains the altered intracellular modification of the cytoskeleton protein complexes involving cadherins and the actin binding proteins during epithelial malignant progression $[34,35]$. This genetic imbalance releases the metastatic process due to disruption of cell-to-cell adhesion. However, further mechanism analysis of E-cadherin and WNT/ $\beta$-catenin in RCCs should be studied in the future, and preclinical studies for potential therapy targets in this signaling should be performed to improve treatment response.

In conclusion, aberrant expression of E-cadherin/ $\beta$ catenin in RCCs participates in metastatic progression. Based on the corresponding gene deregulation mechanisms, there is an increasing need for developing and evaluating inhibitory targets and agents for RCC therapy [36-38]. The expression status of E-cadherin/ $\beta$ catenin should be paid attention in the clinical treatment of RCCs. 
Table 4: Univariate and multivariate analyses of $\beta$-catenin expression in disease-free survival and overall survival

\begin{tabular}{|c|c|c|c|c|c|c|}
\hline \multirow{2}{*}{ Variable analysis } & \multicolumn{3}{|c|}{ Disease-Free Survival } & \multicolumn{3}{|c|}{ Overall Survival } \\
\hline & HR & $95 \% \mathrm{CI}$ & $p$ & HR & $95 \% \mathrm{CI}$ & $p$ \\
\hline Univariate & $N=125$ & & & $N=125$ & & \\
\hline E-cad- $/ \beta$-cat + & 3.433 & $1.249-9.433$ & 0.017 & 8.761 & $1.103-69.556$ & 0.040 \\
\hline Multivariate & $N=125$ & & & $N=125$ & & \\
\hline Gender & 1.029 & $0.371-2.857$ & 0.956 & 0.691 & $0.119-3.473$ & 0.668 \\
\hline Age & 0.371 & $0.137-1.003$ & 0.051 & 0.220 & $0.048-1.340$ & 0.071 \\
\hline Size & 0.620 & $0.171-2.240$ & 0.465 & 0.709 & $0.069-5.115$ & 0.733 \\
\hline Stage & 1.891 & $1.036-3.454$ & 0.038 & 1.903 & $0.874-4.653$ & 0.129 \\
\hline Necrosis & 2.195 & $0.691-6.977$ & 0.183 & 0.954 & $0.212-5.586$ & 0.956 \\
\hline Fuhrman & 1.236 & $0.739-2.066$ & 0.420 & 1.845 & $0.880-4.514$ & 0.150 \\
\hline E-cad-/ $\beta$-cat + & 4.105 & $1.329-12.681$ & 0.030 & 4.006 & $0.903-68.373$ & 0.222 \\
\hline
\end{tabular}

$\mathrm{CI}=$ confidence interval; $\mathrm{HR}=$ hazard ratios.

The variables were compared in the following ways: Age, $\geq 57$ years vs. $<57$ years; Gender, male vs. female; $\beta$-catenin expression, positive vs. negative; size, $>5.25$ vs. $<5.25$; Stage, III-IV vs. I-II; Necrosis, yes vs. no; Fuhrman grade, G3-4 vs. G1-2.

A
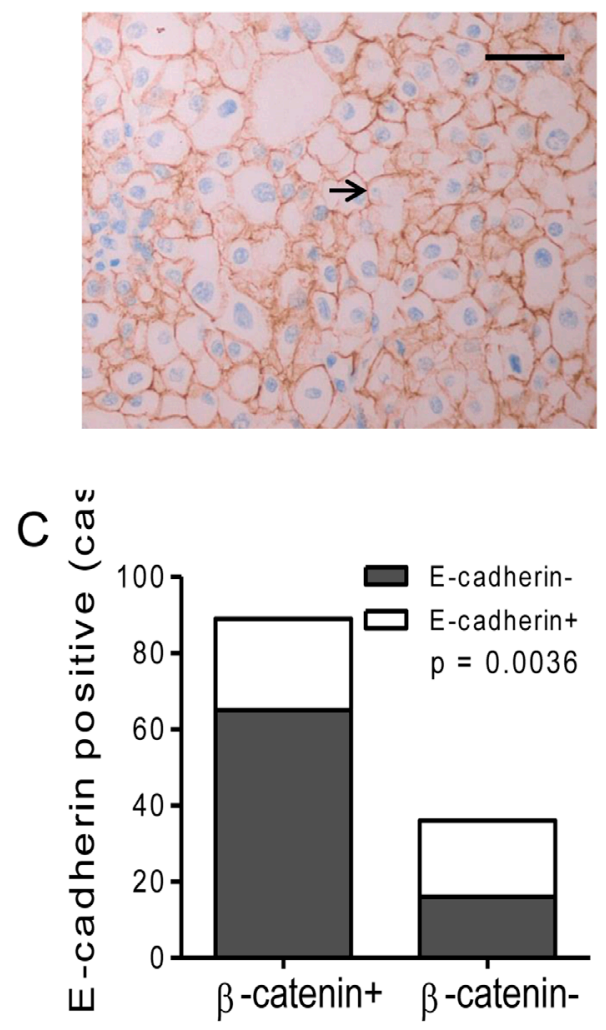

$\mathrm{B}$
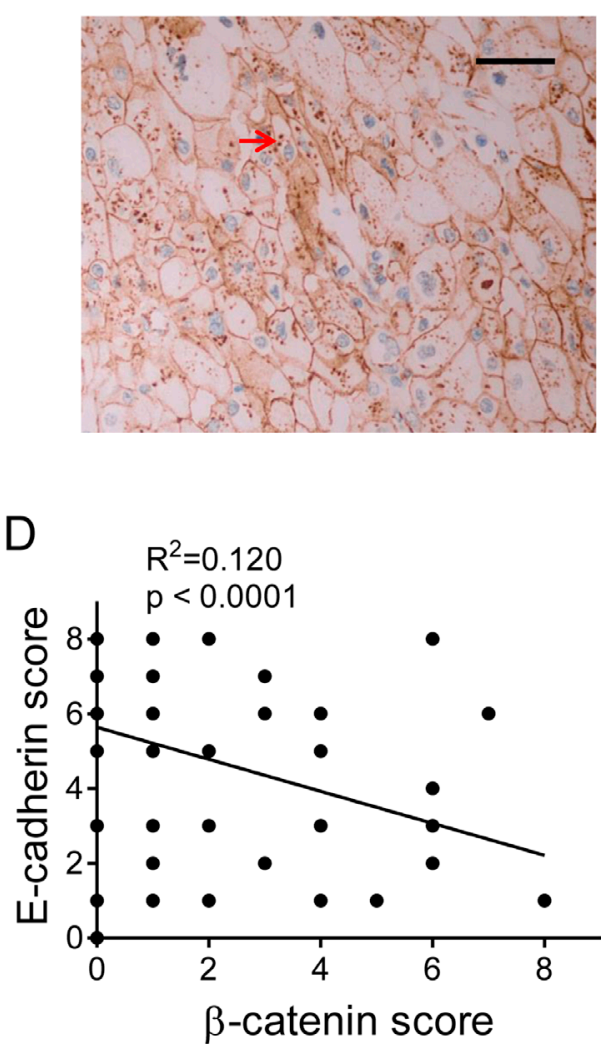

Figure 3: Expression of $\boldsymbol{\beta}$-catenin and correlation with E-cadherin in RCC specimens. (A, B) $\beta$-catenin expression images of RCC specimens. Positive $\beta$-catenin expression was mainly located on the membrane in E-cadherin positive specimen (A, black arrow), and cytoplasmic accumulation of $\beta$-catenin in E-cadherin negative specimen (B, red arrow). Bar, $50 \mu \mathrm{m}$. (C) The percentage of E-cadherin + was compared between $\beta$-catenin positive or negative RCCs. (D) Negative correlation of E-cadherin and $\beta$-catenin expression scores in RCC specimens according to a linear regression. 


\section{MATERIALS AND METHODS}

\section{Patients and samples}

Totally $125 \mathrm{RCC}$ patients were involved in our study. All patients were diagnosed as renal cell carcinomas and underwent surgery between 2003 and 2010 at General Hospital of Jinan Military Region, Shandong, China. Tissue microarray was prepared with collected tumor specimens. Clinical and pathological information was collected including age, gender, tumor size, TNM stage, histological type, necrosis and Fuhrman grade. All patients were followed-up every 6 months, which was carried out by telephone interview, outpatient records or death certificate review. Fresh tissues of renal cell carcinoma were also collected for immunoblotting assays and reverse transcription PCR. Our study was approved by the Ethics
Committee of General Hospital of Jinan Military Region. Informed consent was accepted by the patients according to the research proposals.

\section{Tissue microarray (TMA) and immunohistochemical staining (IHC)}

Hematoxylin- and eosin- (H\&E) staining of each case was performed to confirm diagnosis and select representative area. TMA was established with representative areas of each tumor with a diameter of $2.0 \mathrm{~mm}$ from formalin-fixed, paraffinembedded tissue blocks. TMA sections were prepared at $5 \mu \mathrm{m}$ of thickness for IHC staining according the following steps: deparaffinized in xylene, hydrated with gradient ethanol, antigen retrieval with $0.01 \mathrm{M}$ sodium citrate for 17 minutes and immersed in $3 \% \mathrm{H}_{2} \mathrm{O}_{2}$, incubated with $10 \%$ goat serum. Primary antibodies against human E-cadherin and $\beta$-catenin
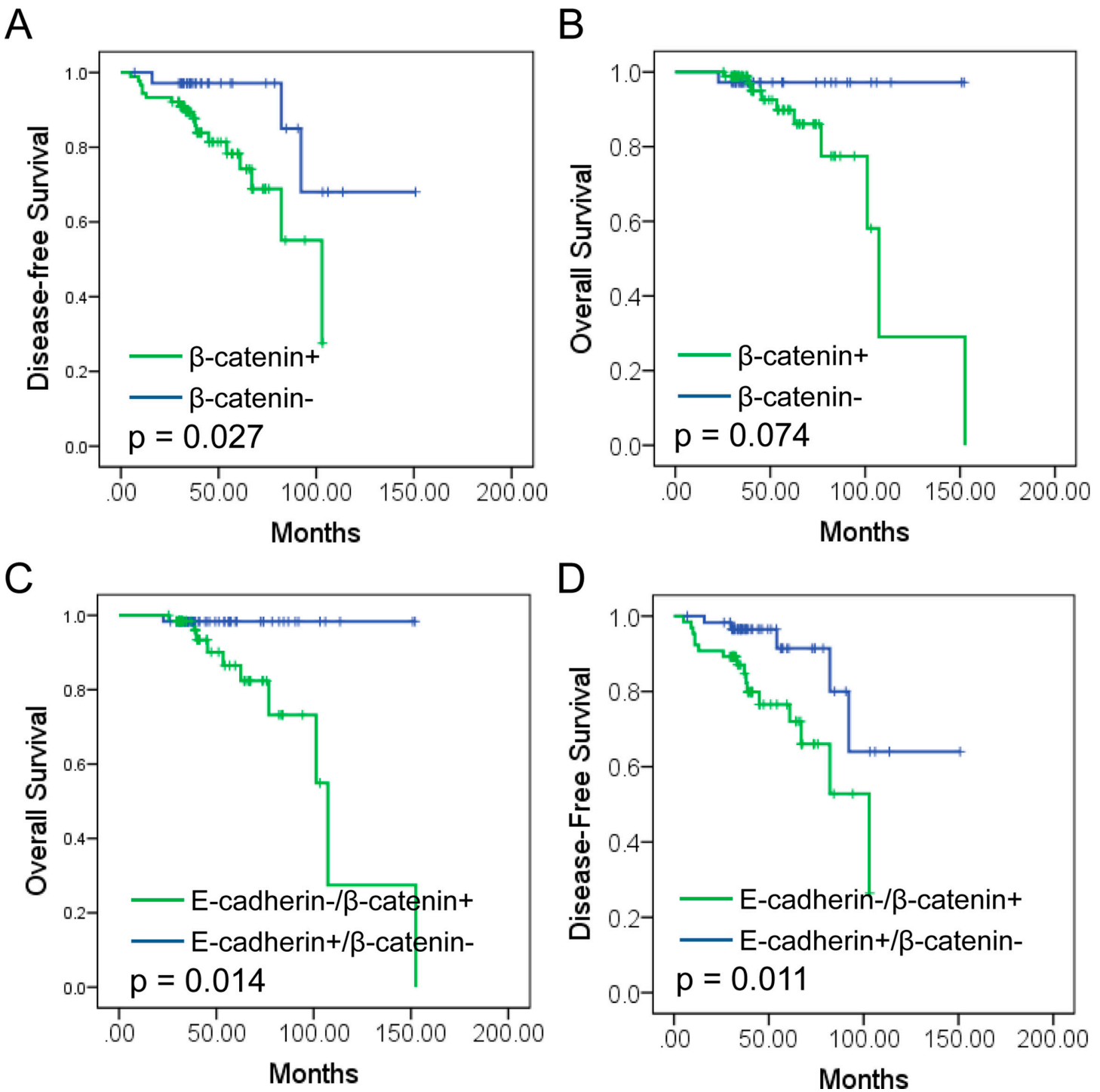

Figure 4: Prognostic value of E-cadherin and $\boldsymbol{\beta}$-catenin expression in RCC. (A, B) Kaplan-Meier analysis of $\beta$-catenin in disease-free survival (DFS, A) and overall survival (OS, B) in RCC patients. (C, D). Kaplan-Meier analysis of E-cadherin/ $\beta$-catenin in disease-free survival (DFS, C) and overall survival (OS, D) in RCC patients. 
(GeneTex, San Antonio, TX) were incubated respectively at $4^{\circ} \mathrm{C}$ overnight. Then the sections were stained with peroxidaseconjugated avidin, followed with 3,3-diaminobenzidine tetrahydrochloride (DAB) and hematoxylin blue was used to counterstain. Assigned IHC positive RCC tissues, whose expression were confirmed by Western blot assays, were stained as positive control. Control IgG with equal concentration was used as negative control in each stain.

\section{IHC evaluation}

The evaluation of E-cadherin and $\beta$-catenin levels was performed with Allred scoring system [39]. Brown membrane staining for E-cadherin and brown membrane and cytoplasm staining for $\beta$-catenin were considered as positive staining. The score for each section was determined by staining intensity and percentage of stained cells. Staining intensity score was arranged into: 0 (no staining), 1 (weak staining), 2 (moderate staining) and 3 (strong staining). Positive percentage score was arranged into: 0 (none); 1 (< $1 \%$ ); $2(1 \%$ to $10 \%) ; 3(10 \%$ to $35 \%) ; 4(35 \%$ to $70 \%)$; and 5 $(>70 \%)$. The sum of intensity score and percentage score was the final score of each case. The score $\geq 4$ was positive and $<4$ was negative with a statistical analysis. IHC evaluation was performed by two pathologists in a blinded manner.

\section{Western blot analysis}

Fresh RCC tissues were collected and homogenized with lysis buffer, which contained $50 \mathrm{mM}$ Tris- $\mathrm{HCl}$, $150 \mathrm{mM} \mathrm{NaCl}, 1 \mathrm{mM}$ EDTA, $1 \mathrm{mM}$ phenylmethylsulfonyl fluoride, $1 \%$ Triton $\mathrm{X}-100,0.1 \% \mathrm{SDS}$, and $0.1 \%$ sodium deoxycholate, $\mathrm{pH}$ 7.2. The homogenates were centrifuged at $1000 \mathrm{~g}$ for $10 \mathrm{~min}$ at $4^{\circ} \mathrm{C}$. The membrane and cytosol fractions were prepared with Membrane and Cytosol Protein Extraction Kit according to the manufacturer $>$ s instructions (Beyotime Institute of Biotechnology, China). Protein concentration of the supernatant was measured by the Bradford method. Equal amounts of proteins $(20 \mu \mathrm{g})$ of each sample were separated on 9\% SDS-PAGE and electroblotted on polyvinylidene fluoride membranes. Blocked membranes were incubated overnight at $4^{\circ} \mathrm{C}$ with antibodies against E-cadherin, $\beta$-catenin cyclinD1 (GeneTex, San Antonio, TX), Na, K-ATPase (Abcam Inc., Cambridge, MA) and $\beta$-actin (Cell Signaling Technology, Beverly, MA), respectively. The membranes were probed respectively with HRP-conjugated secondary antibodies $(1: 4,000)$ at room temperature for $1 \mathrm{~h}$. Immunoreactive protein bands were visualized by use of an enhanced chemiluminescence detection system (GE Biosciences, Buckinghamshire, England) according to the manufacturer's protocol.

\section{Reverse transcription PCR (RT-PCR)}

Total cellular mRNA was extracted from fresh RCC tissues using RNAiso Plus Reagent (TaKaRa, Japan) and reverse-transcribed with 1st Strand cDNA Synthesis Kit (TaKaRa, Japan) according to the introduction. The RNA concentration was determined by Thermo Scientific NanoDrop 2000 detector. Total of $5 \mu \mathrm{g}$ mRNA was used for RT-PCR. Primers for E-cadherin, cyclinD1, c-myc and $\beta$-actin used in our study were listed as below: CDH1forward: AAAGGCCCATTTCCTAAAAACCT; Reverse: TGCGTTCTCTATCCAGAGGCT. CCND1-forward: CAA TGACCCCGCACGATTTC; Reverse: CATGGAGGGC GGATTGGAA. MYC-forward: CACACCCACAATTC AGGAAGAG; Reverse: GACGTGCTACAAGGTGGCA. ACTB-forward: TTTTGGCTATACCCTACTGGCA; Reverse: CTGCACAGTCGTCAGCATATC. RT-PCR was performed with a One Step RT-PCR Kit Ver.2 (TaKaRa, Japan). Each quantity of mRNA expression was corrected by corresponding $\beta$-actin mRNA expression.

\section{Statistical analysis}

The relationship between E-cadherin and $\beta$-catenin expression and clinicopathologic parameters were analyzed using a two- tailed Chi-square test or Fisher's exact test. The correlation between E-cadherin and $\beta$-catenin expression status was analyzed with the Spearman's rank test. Survival estimation was performed with the Kaplan-Meier method and $\log$ rank test. Univariate or multivariate analysis of prognostic factors was analyzed with Cox proportional hazards regression models. All statistical analyses were performed using the SPSS software system (version 19.0; SPSS, Inc., Chicago, IL, USA). $P<0.05$ was considered to be statistically significant.

\section{ACKNOWLEDGMENTS AND FUNDING}

This work was supported by Foundation of Guizhou provincial Science and Technology Department [(2016)1090], United Foundation of Guizhou provincial Science and Technology Department and Guizhou Provincial People's Hospital [LH(2016)7149], Foundation of Guizhou Provincial Health Department (gzwkj2015-1-024), and Science and Technology Program of Guiyang City (2012103)056 and (2016205)007, Natural Science Foundation of Shandong Province (ZR2016HP18).

\section{CONFLICTS OF INTEREST}

The authors declare no conflicts of interests.

\section{REFERENCES}

1. Rodriguez-Cabello MA, Laso-Garcia I, Donis-Canet F, GomezDos-Santos V, Varona-Crespo C, Burgos-Revilla FJ. Renal cell carcinoma with vascular invasion: Mortality and prognostic factors. Actas Urol Esp. 2016.

2. Rini BI, Campbell SC, Escudier B. Renal cell carcinoma. Lancet. 2009; 373:1119-1132. 
3. Ko JJ, Xie W, Kroeger N, Lee JL, Rini BI, Knox JJ, Bjarnason GA, Srinivas S, Pal SK, Yuasa T, Smoragiewicz M, Donskov F, Kanesvaran R, et al. The International Metastatic Renal Cell Carcinoma Database Consortium model as a prognostic tool in patients with metastatic renal cell carcinoma previously treated with first-line targeted therapy: a population-based study. Lancet Oncol. 2015; 16:293-300.

4. Mikami S, Katsube K, Oya M, Ishida M, Kosaka T, Mizuno R, Mukai M, Okada Y. Expression of Snail and Slug in renal cell carcinoma: E-cadherin repressor Snail is associated with cancer invasion and prognosis. Lab Invest. 2011; 91:1443-1458.

5. Conant JL, Peng Z, Evans MF, Naud S, Cooper K. Sarcomatoid renal cell carcinoma is an example of epithelial--mesenchymal transition. J Clin Pathol. 2011; 64:1088-1092.

6. Giroldi LA, Shimazui T, Schalken JA, Yamasaki H, Bringuier PP. Classical cadherins in urological cancers. Morphologie. 2000; 84:31-38.

7. Khawam K, Giron-Michel J, Gu Y, Perier A, Giuliani M, Caignard A, Devocelle A, Ferrini S, Fabbi M, Charpentier B, Ludwig A, Chouaib S, Azzarone B, et al. Human renal cancer cells express a novel membrane-bound interleukin-15 that induces, in response to the soluble interleukin-15 receptor alpha chain, epithelial-to-mesenchymal transition. Cancer Res. 2009; 69:1561-1569.

8. Onder TT, Gupta PB, Mani SA, Yang J, Lander ES, Weinberg RA. Loss of E-cadherin promotes metastasis via multiple downstream transcriptional pathways. Cancer Res. 2008; 68:3645-3654.

9. Chen Y, Huang Q, Zhou H, Wang Y, Hu X, Li T. Inhibition of canonical WNT/beta-catenin signaling is involved in leflunomide (LEF)-mediated cytotoxic effects on renal carcinoma cells. Oncotarget. 2016; 7:50401-50416. doi: 10.18632/oncotarget.10409.

10. Chen HN, Yuan K, Xie N, Wang K, Huang Z, Chen Y, Dou Q, Wu M, Nice EC, Zhou ZG, Huang C. PDLIM1 Stabilizes the E-Cadherin/beta-Catenin Complex to Prevent Epithelial-Mesenchymal Transition and Metastatic Potential of Colorectal Cancer Cells. Cancer Res. 2016; 76:1122-1134.

11. Tseng RC, Lee SH, Hsu HS, Chen BH, Tsai WC, Tzao C, Wang YC. SLIT2 attenuation during lung cancer progression deregulates beta-catenin and E-cadherin and associates with poor prognosis. Cancer Res. 2010; 70:543-551.

12. Kandouz M, Alachkar A, Zhang L, Dekhil H, Chehna F, Yasmeen A, Al Moustafa AE. Teucrium polium plant extract inhibits cell invasion and motility of human prostate cancer cells via the restoration of the E-cadherin/catenin complex. J Ethnopharmcol. 2010; 129:410-415.

13. Su Y, Simmen RC. Soy isoflavone genistein upregulates epithelial adhesion molecule E-cadherin expression and attenuates beta-catenin signaling in mammary epithelial cells. Carcinogenesis. 2009; 30:331-339.
14. Nakamoto M, Hisaoka M. Clinicopathological Implications of Wingless/int1 (WNT) Signaling Pathway in Pancreatic Ductal Adenocarcinoma. J UOEH. 2016; 38:1-8.

15. Xu Q, Krause M, Samoylenko A, Vainio S. Wnt Signaling in Renal Cell Carcinoma. Cancers. 2016; 8.

16. Billfeldt NK, Banyai D, Kovacs G. Absence of Canonical WNT Signaling in Adult Renal Cell Tumors of Embryonal Origin. Anticancer Res. 2016; 36:2169-2173.

17. Tian X, Liu Z, Niu B, Zhang J, Tan TK, Lee SR, Zhao Y, Harris DC, Zheng G. E-cadherin/beta-catenin complex and the epithelial barrier. J Biomed Biotechnol. 2011; 2011:567305.

18. Gottardi CJ, Wong E, Gumbiner BM. E-cadherin suppresses cellular transformation by inhibiting beta-catenin signaling in an adhesion-independent manner. J Cell Biol. 2001; 153:1049-1060.

19. Shamir ER, Ewald AJ. Adhesion in mammary development: novel roles for E-cadherin in individual and collective cell migration. Curr Top Dev Biol. 2015; 112:353-382.

20. Wang J, Lei ZJ, Guo Y, Wang T, Qin ZY, Xiao HL, Fan LL, Chen DF, Bian XW, Liu J, Wang B. miRNAregulated delivery of lincRNA-p21 suppresses beta-catenin signaling and tumorigenicity of colorectal cancer stem cells. Oncotarget. 2015; 6:37852-37870. doi: 10.18632/ oncotarget.5635.

21. Wang B, Liu J, Ma LN, Xiao HL, Wang YZ, Li Y, Wang Z, Fan L, Lan C, Yang M, Hu L, Wei Y, Bian XW, et al. Chimeric 5/35 adenovirus-mediated Dickkopf-1 overexpression suppressed tumorigenicity of CD44(+) gastric cancer cells via attenuating Wnt signaling. J Gastroenterol. 2013; 48:798-808.

22. Braungart E, Schumacher C, Hartmann E, Nekarda H, Becker KF, Hofler H, Atkinson MJ. Functional loss of E-cadherin and cadherin-11 alleles on chromosome 16q22 in colonic cancer. J Pathol. 1999; 187:530-534.

23. Liu L, Xu Z, Zhong L, Wang H, Jiang S, Long Q, Xu J, Guo J. Enhancer of zeste homolog 2 (EZH2) promotes tumour cell migration and invasion via epigenetic repression of E-cadherin in renal cell carcinoma. BJU Int. 2016; 117:351-362.

24. Liontos M, Trigka EA, Korkolopoulou P, Tzannis K, Lainakis G, Koutsoukos K, Kostouros E, Lykka M, Papandreou CN, Karavasilis V, Christodoulou C, Papatsoris A, Skolarikos A, et al. Expression and prognostic significance of VEGF and mTOR pathway proteins in metastatic renal cell carcinoma patients: a prognostic immunohistochemical profile for kidney cancer patients. World J Urol. 2016.

25. Zeng L, Bai M, Mittal AK, El-Jouni W, Zhou J, Cohen DM, Zhou MI, Cohen HT. Candidate tumor suppressor and pVHL partner Jade-1 binds and inhibits AKT in renal cell carcinoma. Cancer Res. 2013; 73:5371-5380.

26. Rasmussen N, Rathmell WK. Looking beyond inhibition of VEGF/mTOR: emerging targets for renal cell carcinoma drug development. Curr Clin Pharmacol. 2011; 6:199-206. 
27. Massari F, Ciccarese C, Santoni M, Brunelli M, Piva F, Modena A, Bimbatti D, Fantinel E, Santini D, Cheng L, Cascinu S, Montironi R, Tortora G. Metabolic alterations in renal cell carcinoma. Cancer Treat Rev. 2015; 41:767-776.

28 VON Schulz-Hausmann SA, Schmeel LC, Schmeel FC, Schmidt-Wolf IG. Targeting the Wnt/beta-catenin pathway in renal cell carcinoma. Anticancer Res. 2014; 34:41014108.

29. Zhao J, He Q, Gong Z, Chen S, Cui L. Niclosamide suppresses renal cell carcinoma by inhibiting Wnt/ beta-catenin and inducing mitochondrial dysfunctions. SpringerPlus. 2016; 5:1436.

30. Ueno K, Hirata H, Majid S, Chen Y, Zaman MS, Tabatabai ZL, Hinoda Y, Dahiya R. Wnt antagonist DICKKOPF-3 (Dkk-3) induces apoptosis in human renal cell carcinoma. Mol Carcinog. 2011; 50:449-457.

31. Kruck S, Eyrich C, Scharpf M, Sievert KD, Fend F, Stenzl A, Bedke J. Impact of an altered Wnt1/beta-catenin expression on clinicopathology and prognosis in clear cell renal cell carcinoma. Int J Mol Sci. 2013; 14:10944-10957.

32. Salon C, Lantuejoul S, Eymin B, Gazzeri S, Brambilla C, Brambilla E. The E-cadherin-beta-catenin complex and its implication in lung cancer progression and prognosis. Future Oncol. 2005; 1:649-660.

33. Ronkainen H, Kauppila S, Hirvikoski P, Vaarala MH. Evaluation of myosin VI, E-cadherin and beta-catenin immunostaining in renal cell carcinoma. J Exp Clin Cancer Res. 2010; 29:2.

34. Ladoux B, Nelson WJ, Yan J, Mege RM. The mechanotransduction machinery at work at adherens junctions. Integr Biol (Camb). 2015; 7:1109-1119.

35. Algaba F, Arce Y, Fernandez S, Oliver A, Alcaraz A. Adhesion molecules expression as a potential marker of prostate cancer aggressivity. A TMA study of radical prostatectomy specimens. Arch Ital Urol Androl. 2006; 78:130-134.

36. Wang Q, Zhang W, Yang J, Liu YL, Yan ZX, Guo ZJ, Li YJ, Bian XW. High ERalpha36 Expression Level and Membrane Location Predict Poor Prognosis in Renal Cell Carcinoma. Medicine. 2015; 94:e1048.

37. Curtis SA, Cohen JV, Kluger HM. Evolving Immunotherapy Approaches for Renal Cell Carcinoma. Curr Oncol Rep. 2016; 18:57.

38. Kambhampati S, Banerjee S, Dhar K, Mehta S, Haque I, Dhar G, Majumder M, Ray G, Vanveldhuizen PJ, Banerjee SK. 2-methoxyestradiol inhibits Barrett's esophageal adenocarcinoma growth and differentiation through differential regulation of the beta-catenin-E-cadherin axis. Mol Cancer Ther. 2010; 9:523-534.

39. Akbar S, Jordan LB, Purdie CA, Thompson AM, McKenna SJ. Comparing computer-generated and pathologist-generated tumour segmentations for immunohistochemical scoring of breast tissue microarrays. Br J Cancer. 2015; 113:1075-1080. 